\title{
INTENSITY OF THE HEAT TRANSFER IN RADIATION RECUPERATORS
}

\author{
Rayko Stanev, Daniela Choshnova* and Sevgin Velibashev \\ University of Chemical Technology and Metallurgy, \\ 8, St. Kl. Ohridski Blvd, 1756 Sofia, Bulgaria, \\ e-mails: stanev@uctm.edu; daniela_choshnova@abv.bg; sicha@abv.bg
}

\begin{abstract}
The significance of the units, utilizing the flue gas heat for increase of the performance and along with it - also of the energy, ecological and economic efficiency in the contemporary industrial objects, is pointed out. An analysis of the indicators, characterizing a steel radiation recuperator pipe-in-pipe type, is fulfilled. The problems at the design heat-technical dimensioning of these utilizing units as well as the recommended in the literature borders for selection of the velocities at normal conditions of the passing through them flue gas and air are discussed. The main calculations are conducted by means of our own software product. The analysis of the gained results shows that a part of them has a confirming character, but there are also such ones which are not quite expected mostly in quantitative relationship. The last are commented and on the basis of them some concrete conclusions and recommendations for a more confident correction of the initially preset values of the indicators, determining the streamline load of the radiation recuperator, are formulated.
\end{abstract}

Keywords: radiation recuperators, energy, ecology, efficiency.

\section{INTRODUCTION}

A big part of the furnaces and aggregates, operating in the metallurgical industry, has a low performance. One of the main reasons for that situation is the significant loss of heat brought out with the flue gas, which represents a basic secondary energy resource [1]. In order to raise that indicator, behind the mentioned aggregates utilizing units are installed, using the heat of the outgoing combustion products.

The most widespread apparatuses for a beneficial decrease of the temperature of the flue gas, leaving the corresponding furnace, are the recuperators,

\footnotetext{
${ }^{*}$ Corresponding author.

DOI: 10.7546/EngSci.LVI.19.01.02
}

(c) Инженерни науки, год. LVI, 2019, № 119 (c) Engineering Sciences, LVI, 2019, No. 1 
which are bricked under the floor level or above the arch. In them, a complex (total) heat transfer from the flue gas to the air is realized necessary for the fulfillment of the oxidative reactions. Except for it, the discussed units allow a preliminary enhancement of the temperature of the used gaseous fuel also.

With the preheating of some of the mentioned ingoing flows (or simultaneously of both) different positive effects could be achieved in the treated technological object. The most essential and universally valid among them are the limitation of the consumption of primary energy resources and the increase of the performance of the aggregate, examined in detail in our previous publications $[2,3,4]$. It gives the possibility of using lower-caloric fuels, which is of essential importance for the reduction of the prime cost of the production and impacts on the complex technical-economical results of the industrial enterprises. In that way a promotion of their energy and ecological efficiency is also ensured.

In the present paper an analysis of the indicators of one of the most widespread in the metallurgical practice constructions of steel recuperators - this of radiation apparatus pipe-in-pipe type, is implemented. It is accepted that this apparatus is used for air preheating under different operating conditions, varying from minimum to maximum streamline load of the device.

\section{EXPERIMENTAL}

The constructive arrangement and the function of the recuperators are described in detail in a number of other $[5,6,7,8,9]$ and our $[2,3,4,10$, $11,12]$ publications. In many of them a special attention is paid to the heattechnical dimensioning of the most widespread types of such apparatuses. At all procedures, inclusively these for the radiation utilizing units, after the initial fulfillment of the calculations, it comes usually to results unacceptable from constructive point of view, concerning mainly the composition. Then, the insight and the experience of the designer are of decisive importance.

Among the indicators assumed as most directly influencing on the calculations are the velocities of the flue gas and the air at normal conditions. It is obvious the general regularity that their enhancement arouses an intensification of the heat transfer in the utilizing unit, which makes it compacter. Regarding the heated medium this expected tendency should not be brought in question. However, it is not so unambiguously the influence of the increased smoke velocity. On the one hand, it leads to raising of the convective component of the heat transfer coefficient from the combustion products to the partitioning wall owing to the increased turbulence of their flow. But on the

(c) Инженерни науки, год. LVI, 2019, № 1

(C) Engineering Sciences, LVI, 2019, No. 1 
other hand, the necessary cross-section of the cylinder, through which the motion is implemented, becomes smaller and so the radiating volume of the flue gas diminishes and thence the energy emitted from it.

To increase the confidence in the often necessary correction of the initially preset values of the indicators, characterizing the streamline load of the radiation recuperator, the present research is conducted.

The discussed apparatus represents two vertically situated coaxial cylinders. Through the inner of them the flue gas moves from below upwards, but via the space between the two pipes with an annular cross-section the air passes from above downwards.

In Figure 1 the basic dimensions of the discussed utilizing unit are shown sketchily.

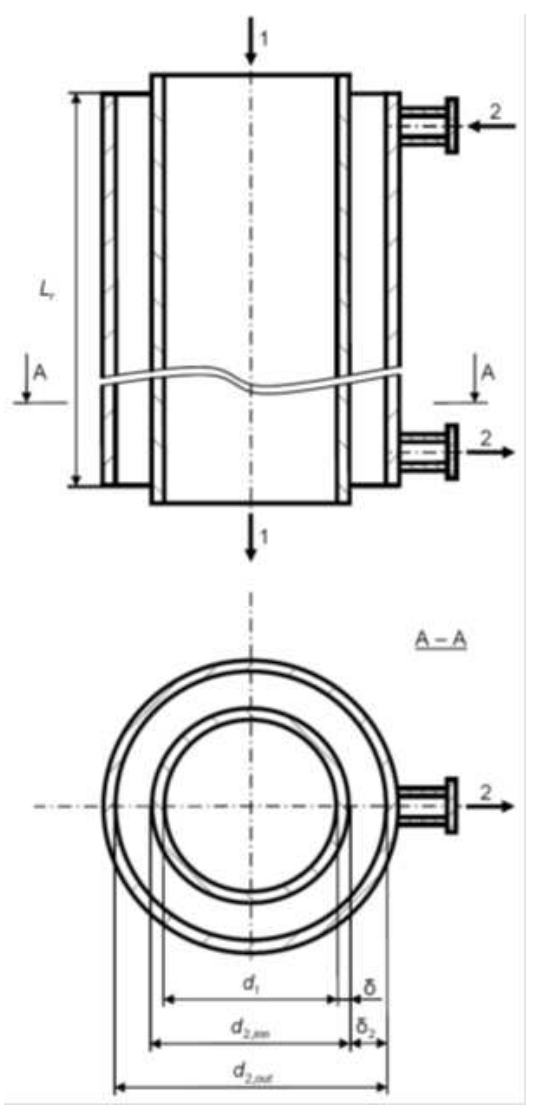

Fig. 1. Vertical and horizontal sections of the designed radiation recuperator pipe-in-pipe type: 1 - flue gas; 2 - air 
For the intervals of recommendatory velocities of the flue gas and the air at normal conditions in radiation apparatuses different data are suggested, from among which the selection of their concrete levels is realized. For example, in some representatives of the older specialized literature, the borders $1.5 \div 5$ $\mathrm{m} / \mathrm{s}$ and $15 \div 30 \mathrm{~m} / \mathrm{s}$ [13] or $3 \div 5 \mathrm{~m} / \mathrm{s}$ and $20 \div 30 \mathrm{~m} / \mathrm{s} \mathrm{[14]} \mathrm{are} \mathrm{pointed} \mathrm{out,}$ respectively. There are also cases, when for the velocity of the heating fluid under normal conditions it does not make difference between the separate constructions of steel recuperators, and it is recommended this parameter to be from 3 to $5 \mathrm{~m} / \mathrm{s}$, but for this one of the cold medium the range $20 \div 30 \mathrm{~m} / \mathrm{s}$ is proposed again [1]. In the contemporary sources, essentially raised values of the air indicators could be detected, for example from 20 to $50 \mathrm{~m} / \mathrm{s}$ too [15]. Naturally, they could arouse enhanced streamline losses. It should be resorted to their using after an exhaustive technical-economical analysis, which compares the total expenses for the implementation of each from the projects through our own procedure, taking into account both the capital investments for the constructing of the utilizing units and the operating costs related with them $[3,12]$.

However, the intervals that occur most often $[6,8]$ are also adopted in this work and given in Table 1. The basic indicators of the recuperator are also systematized, representing an input at the conducted heat-technical calculations. In consequence of the striving for achievement of recuperators efficient in energy and technical-economical relationship, as a lower border of the air velocity at normal conditions the level $20 \mathrm{~m} / \mathrm{s}$ is preferred, which is available in the most of the cited publications $[1,6,8,14]$.

It is assumed that the concrete calculations are conducted at six levels of velocities of the flue gas and the air, which are chosen with a view to be included entirely the selected intervals of their values. These combinations are presented in Table 2. As it makes an impression, in the chosen six variants each of the velocities of the media is situated in the same place within the framework of the corresponding range. The first series of calculations is realized for their lower borders. At the next ones the values are increased with $25,50,75$ and $90 \%$ of the interval width, as the last variant is realized at their maximum permissible levels according to Table 1 and the explanations given above. Through the already mentioned and completely justified enhanced interest to the more intensive function of utilizing units, the alteration pitch around the superior limits of the ranges is reduced from 25 to $10 \%$.

Therefore, the calculation of each of both the velocities at normal conditions $w_{0, i}[\mathrm{~m} / \mathrm{s}]$, for example at the penultimate largest level, is fulfilled by the formula:

(c) Инженерни науки, год. LVI, 2019, № 122 (c) Engineering Sciences, LVI, 2019, No. 1 


$$
w_{i, 0}=w_{i, 0}^{\min }+0.9\left(w_{i, 0}^{\max }-w_{i, 0}^{\min }\right),
$$

where its upper and lower borders are marked with $w_{i, 0}^{\max }$ and $w_{i, 0}^{\min }$, respectively, as according to Fig. 1, for the flue gas $i=1$, and for the air $i=2$.

For a realization of the main part of the design heat-technical dimensioning

TABLE 1. Data for the considered utilizing device

\begin{tabular}{|r|l|c|c|c|}
\hline No & \multicolumn{1}{|c|}{ Indicator } & Symbol & Unit & Value/Explication \\
\hline 1 & Recuperator type & - & - & $\begin{array}{c}\text { Radiation, } \\
\text { pipe-in-pipe type }\end{array}$ \\
\hline 2 & Motion scheme of the media & - & - & $\begin{array}{c}\text { Counter-current } \\
\text { flow }\end{array}$ \\
\hline 3 & Inlet flue gas temperature & $T_{1}^{\prime}$ & $\mathrm{K}$ & 1473 \\
\hline 4 & Outlet flue gas temperature & $T_{1}^{\prime \prime}$ & $\mathrm{K}$ & 1144 \\
\hline 5 & Inlet air temperature & $T_{2}^{\prime}$ & $\mathrm{K}$ & 293 \\
\hline 6 & Outlet air temperature & $T_{2}^{\prime \prime}$ & $\mathrm{K}$ & 673 \\
\hline 7 & $\begin{array}{l}\text { Volumetric flow rate of the flue gas } \\
\text { at normal conditions }\end{array}$ & $\dot{V}_{1,0}$ & $\mathrm{~m}^{3} / \mathrm{s}$ & 2.6 \\
\hline 8 & $\begin{array}{l}\text { Volumetric flow rate of the air at } \\
\text { normal conditions }\end{array}$ & $\dot{V}_{2,0}$ & $\mathrm{~m}^{3} / \mathrm{s}$ & 2.4 \\
\hline 9 & $\begin{array}{l}\text { Flue gas velocity at normal condi- } \\
\text { tions }\end{array}$ & $w_{1,0}$ & $\mathrm{~m} / \mathrm{s}$ & $3 \div 5$ \\
\hline 10 & Air velocity at normal conditions & $w_{2,0}$ & $\mathrm{~m} / \mathrm{s}$ & $20 \div 30$ \\
\hline 11 & Wall thickness of the inner cylinder & $\delta$ & $\mathrm{m}$ & 0.006 \\
\hline 12 & $\begin{array}{l}\text { Carbon dioxide contents in the flue } \\
\text { gas }\end{array}$ & $\mathrm{CO}_{2}$ & $\mathrm{vol. \%}$ & 9.05 \\
\hline 13 & Water steam contents in the flue gas & $\mathrm{H}_{2} \mathrm{O}$ & $\mathrm{vol. \%}$ & 19.17 \\
\hline 14 & Oxygen contents in the flue gas & $\mathrm{O}_{2}$ & vol.\% & 0.89 \\
\hline 15 & Nitrogen contents in the flue gas & $\mathrm{N}_{2}$ & vol.\% & 70.89 \\
\hline
\end{tabular}

TABLE 2. Variants for fulfillment of the calculations depending on the preset values at normal conditions, as well as a streamline load degree of the recuperator

\begin{tabular}{|l|c|c|c|c|c|c|}
\hline \multicolumn{1}{|c|}{ Variant No } & 1 & 2 & 3 & 4 & 5 & 6 \\
\hline $\begin{array}{l}\text { Flue gas velocity at normal conditions, } \\
\mathrm{m}^{3} / \mathrm{s}\end{array}$ & 3.0 & 3.5 & 4.0 & 4.5 & 4.8 & 5.0 \\
\hline Air velocity at normal conditions, $\mathrm{m}^{3} / \mathrm{s}$ & 20.0 & 22.5 & 25.0 & 27.5 & 29.0 & 30.0 \\
\hline $\begin{array}{l}\text { Exceeding of the chosen values over their } \\
\text { lower borders, } \%\end{array}$ & 0 & 25 & 50 & 75 & 90 & 100 \\
\hline
\end{tabular}

(c) Инженерни науки, год. LVI, 2019, № 1 
of the radiation recuperator ours own software product is used, which is based on the conventional procedures for similar calculations $[1,5,7,16,17]$. Its working capacity and accuracy are proven [3]. A flowchart of this program is offered in [11].

\section{RESULTS AND DISCUSSION}

In Figures 2 and 3, the alterations of the heat transfer coefficient are shown through convection $\alpha_{1}^{k}\left[\mathrm{~W} /\left(\mathrm{m}^{2} . \mathrm{K}\right)\right]$ and radiation $\alpha_{1}^{r}\left[\mathrm{~W} /\left(\mathrm{m}^{2} . \mathrm{K}\right)\right]$, respectively, from the flue gas to the partitioning wall between both the fluids for each of the simulated six regimes of their motion via the utilizing unit. In the first of them a fluent increase of the convective component with the growth of the velocities of the passing media is observed quite logical, as in the case the influence of the flue gas is much more essential. This march is owed to the intensification of the convective heat transfer at the heightening of the increased turbulence degree of the flow. The situation in Fig. 3 is just converse, from which it is seen the reducing of the indicator $\alpha_{1}^{r}$ on account of the gradually drop of the radiating volume of the combustion products (in order to implementing the raising of their velocity) and thence - of the energy emitted from the smoke.

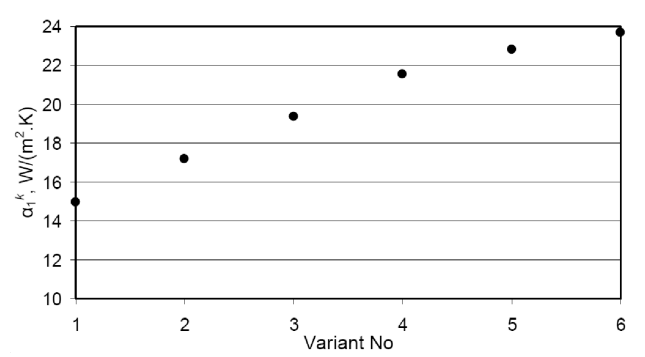

Fig. 2. Convective component of the heat transfer coefficient from the flue gas to the inner surface of the inner cylinder at the separate variants for a streamline load of the recuperator

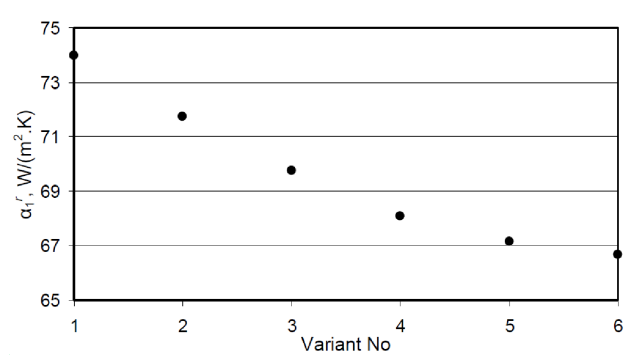

Fig. 3. Radiative component of the heat transfer coefficient from the flue gas to the inner surface of the inner cylinder at the separate variants for a streamline load of the recuperator

The combining of the described trends is presented in Fig. 4. It turns out that at the lowest levels of the velocities (variants 1 and 2), both the effects are mutually counterbalancing, and a practical constancy of the summational heat transfer coefficient from the flue gas to the partitioning wall between the media transported through the utilizing unit $\alpha_{1}\left[\mathrm{~W} /\left(\mathrm{m}^{2} . \mathrm{K}\right)\right]$ is achieved. Its values, however, are smaller than these ones obtained at increase of the streamline

(c) Инженерни науки, год. LVI, 2019, № 124 (c) Engineering Sciences, LVI, 2019, No. 1 


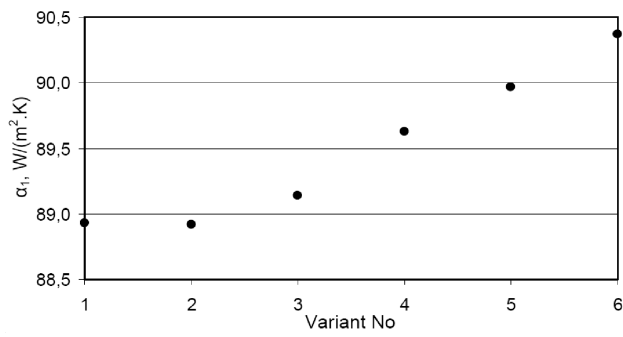

Fig. 4. Summational heat transfer coefficient from the flue gas to the inner surface of the inner cylinder at the separate variants for a streamline load of the recuperator

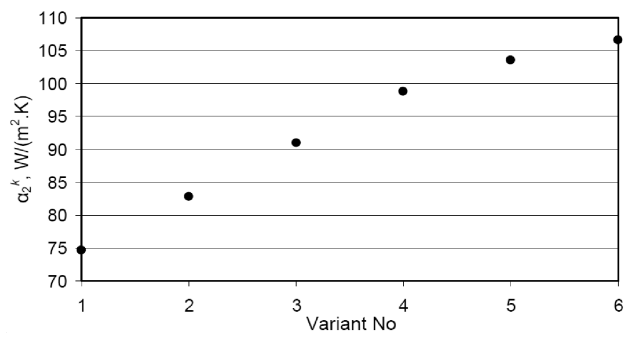

Fig. 5. Heat transfer coefficient from the outer surface of the inner cylinder to the air at the separate variants for a streamline load of the recuperator

load of the recuperator only with about $1.6 \%$. From here, it ensues exactly the first more untrivial conclusion owing to the fulfilled research, namely that regardless of the considerable alterations of the separate components of the heat transfer coefficient from the combustion products to the inner surface of the inner cylinder of the radiation recuperator, the influence of their enhanced velocity is insignificantly. Hence, at equal other conditions, this measure is not justified from a technical-economical point of view, as it leads to a slight intensification of the heat transfer from the smoke side and substantially will increase the operating costs for the transport of this gas.

For the observed growth in Fig. 5 of the convective heat transfer coefficient from the partitioning wall of the utilizing unit to the air $\alpha_{2}\left[\mathrm{~W} /\left(\mathrm{m}^{2} . \mathrm{K}\right)\right]$, it is valid an analogical explanation to that one given in connection with qualitatively the same situation, shown in Fig. 2. As the preheating of the cold fluid is practically fulfilled only through this mechanism [14], the aspiration for enhancement of the indicator $\alpha_{2}$ is acquitted because in the considered case it leads to its raising with about $43 \%$ by alteration of the air velocity at normal conditions from 20 to $30 \mathrm{~m} / \mathrm{s}$.

Since the displayed in Fig. 1 inner cylinder is thin-walled, for the calculation of the total heat transfer coefficient from the flue gas through the wall to the air $k\left[\mathrm{~W} /\left(\mathrm{m}^{2} \cdot \mathrm{K}\right)\right]$, the simpler formula for a flat surface is used. From it, in consideration of the precondition for the neglect ability of the thermal resistance of the wall $\delta / \lambda\left[\mathrm{m}^{2} \cdot \mathrm{K} / \mathrm{W}\right]$, it is obtained:

$$
k=\frac{1}{\frac{1}{\alpha_{1}}+\frac{\delta}{\lambda}+\frac{1}{\alpha_{2}}}=\frac{1}{\frac{1}{\alpha_{1}}+\frac{1}{\alpha_{2}}}=\frac{\alpha_{1} \alpha_{2}}{\alpha_{1}+\alpha_{2}},
$$




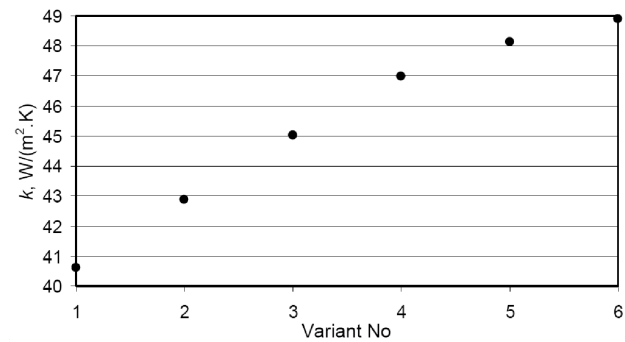

Fig. 6. Total heat transfer coefficient from the flue gas, trough the wall, to the air at the separate variants for a streamline load of the recuperator

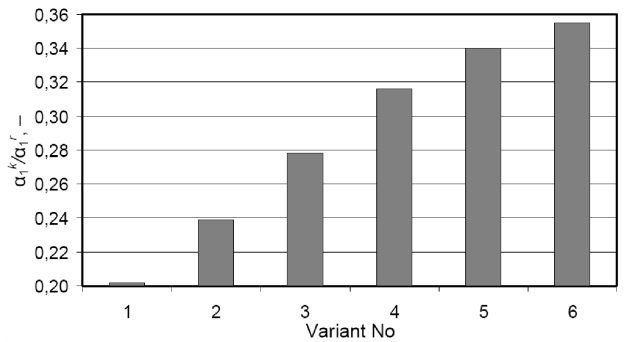

Fig. 7. Ratio between the convective and the radiative components of the heat transfer coefficient from the flue gas to the inner surface of the inner cylinder at the separate variants for a streamline load of the recuperator

where the heat conductivity coefficient of the steel is marked with $\lambda[\mathrm{W} /(\mathrm{m} . \mathrm{K})]$.

In Figure 6 the values of the total heat transfer coefficient for each of the six variants are shown. It is obvious the trend to its growth, which exceeds $20 \%$ at alteration of the velocities of both media between their lower and upper borders.

Figure 7 illustrates the dimensionless quotient $\alpha_{1}^{k} / \alpha_{1}^{r}$ that with the raising of the velocities of both the devices (at predominating significance of this one of the flue gas) between their lower and upper borders changes from 0.202 to 0.355 , i. e. with more than $75 \%$. Notwithstanding the enhancement of the convective part when the velocities grow, the radiation remains as a dominant mechanism, which acquits the name of the considered utilizing unit.

It follows from formula (2) that a best balance, i. e. a most effective reclaiming of the potential of the fluids at their selected parameters and thence - an relatively biggest total heat transfer coefficient, would be achieved at $\alpha_{1} / \alpha_{2} \approx 1$. Figure 8 shows the values of this quotient established at the conducted calculations. From it, a trend to a permanent decrease of the discussed ratio could be seen, which at the lowest velocities amounts to 1.191, and at the highest ones drops to 0.848 . The analysis of its behavior enforces the conclusion that in the considered cases a closest to 1 value will be obtained at selection of velocities, which tend to, but are smaller than the average levels for the corresponding intervals. This result also ought to be accepted as a not entirely expected, still further as an intuitive aspiration to more intensive in streamline point of view operating regimes of the recuperators exists. The recommendation, which could be made in connection with this graph, is that the results from it have to be respected and compared with these from Fig. 7 .

(c) Инженерни науки, год. LVI, 2019, № 126 (c) Engineering Sciences, LVI, 2019, No. 1 


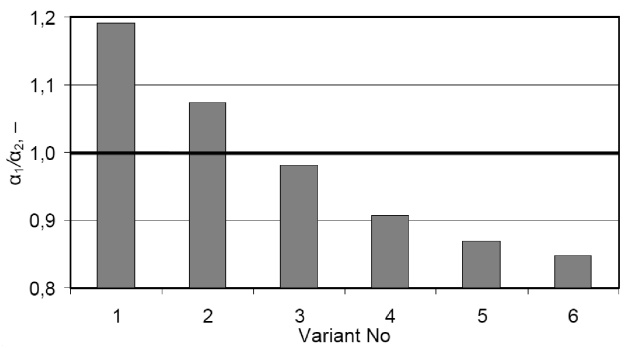

Fig. 8. Ratio between the heat transfer coefficients from the flue gas to the inner surface of the inner cylinder and from its outer surface to the air at the separate variants for a streamline load of the recuperator

Then, after the outlining of several enough good variants, the final constructive solution should be put under an exhaustive technical-economical analysis $[3,12]$.

\section{CONCLUSIONS}

The results from the implemented research of the intensity of the heat transfer in one of the most widespread in the metallurgical practice constructions of steel recuperators - this of radiation apparatus pipe-in-pipe type, could be generalized in such a way.

The fulfilled analysis of the indicators of the utilizing unit at different operating conditions, varying from minimum to maximum streamline load of it, shows the essential influence of the velocities of the flue gas and the heat transfer intensity.

A part of the obtained results are not quite expected mostly in quantitative relationship. As such ones can be pointed out:

- the slight impact of the flue gas velocity on the summational heat transfer coefficient from them to the inner cylinder of the recuperator;

- the significant increase of the ratio between the convective and the radiative components of the same indicator at the alteration of the combustion products velocity from the lower to the upper borders of it;

- the achievement of an optimal quotient, amounting to 1 , between the intensity of the heat transfer from the hot medium to the wall and from it to the cold fluid at velocities of both the flows, which are lower than the average levels for the selected interval of their varying.

(c) Инженерни науки, год. LVI, 2019, № 127

(C) Engineering Sciences, LVI, 2019, No. 1 


\section{REFERENCES}

[1] V. A. KRIVAndin et al., Metallurgical heat engineering, v. II, Moscow, Metallurgy (1986) (in Russian).

[2] R. D. Stanev, V. I. Petkov and E. G. Mihailov, Improvement of thermal work the dryers for the steel-pouring ladles in "Kremikovtzi" LTD, Reports of the International Conference "The Efficient Use of Energy in Metallurgy", Varna, 22-24.06.1999, pp. 185-190.

[3] R. D. Stanev, Technical-economical assessment of the efficiency of hightemperature industrial objects, Academic Publications, Sofia (2011) (in Bulgarian).

[4] R. D. Stanev, Extension of the interrepairing period of metal recuperative heat exchangers, Journal of Chemical Technology and Metallurgy (2014) 49 (4) 418-424.

[5] D. Annaratone, Handbook for heat exchangers and tube banks design, Springer, Heidelberg, New York (2010).

[6] S. KNEzEvic et al., Radiant recuperator modeling and design, Thermal Science (2017) 17 (2) 1119-1134.

[7] H. Martin, Wärmeübertrager, Stuttgart, New York, Georg Thieme Verlag (1988).

[8] I. S. Mitov, Comparative analysis of the energy efficiency of metal recuperators with a different design, Journal of the University of Chemical Technology and Metallurgy - Sofia (2011) 46 (4) 427-432.

[9] www.ornl.gov/sci/ees/itp/documents/FnlRptRecuperatorsFinal.pdf

[10] R. D. Stanev, Nachrechnung von Rekuperatoren, Möglichkeiten zur Lösung der inversen Aufgabe bei wärmetechnischen Berechnungen von Rekuperatoren mit Metallrohren, KI Luft- und Kältetechnik (2004) 40 (2) 67-70.

[11] R. D. Stanev and S. I. Velibashev, Influence of some regime parameters on the construction and the price of recuperators in metallurgy. Part 1: Heattechnical calculations and analyses, Engineering Sciences (2011) XLVIII (3) 59-71 (in Bulgarian).

[12] R. D. Stanev and S. I. Velibashev, Influence of some regime parameters on the construction and the price of recuperators in metallurgy. Part 2: Technicaleconomical calculations and analyses, Engineering Sciences (2011) XLVIII (4) 51-65 (in Bulgarian).

[13] S. VAsilkova et al., Dimensioning of heating and thermal furnaces - a handbook, Metallurgy, Moscow (1983) (in Russian).

[14] B. S. Mastriukov, Theory, design and dimensioning of metallurgical furnaces, v.2: Dimensioning of metallurgical furnaces, Moscow, Metallurgy (1986) (in Russian).

(c) Инженерни науки, год. LVI, 2019, № 128

(C) Engineering Sciences, LVI, 2019, No. 1 
[15] D. Musat and M. Udriste, Model and computer program for radiation dimensioning air heaters used heating furnaces, The Scientific Bulletin of Valahia University, Targoviste, Materials and Mechanics (2012) 10 (7) 23-28.

[16] F. HeLl, Wärmeübertrager, R. Oldenbourg Verlag, München, Wien (1992).

[17] A. TheKd et al., Materials for industrial heat recovery systems. Task 1: Improved materials and operation of recuperators for aluminium melting furnaces, final report, Technical Information Center Oak Ridge, Tennessee, 30.09.2007.

\title{
ИНТЕНЗИВНОСТ НА ТОПЛООБМЕНА В РАДИАЦИОННИ РЕКУПЕРАТОРИ
}

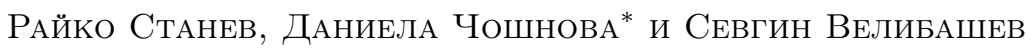 \\ Химикотехнологичен и металургичен университет \\ бул. „Св. Климент Охридски“ №8, 1756 София, Бблгария, \\ e-mails: stanev@uctm.edu; daniela_choshnova@abv.bg; sicha@abv.bg
}

Резюме. Подчертано е значението на съоръженията за утилизация на топлината на димните газове за повишаване на коефициента на полезно действие, а заедно с това - и на енергийната, екологичната и икономическата ефективност на съвременните индустриални обекти. Осъществен е анализ на показателите, характеризиращи стоманен радиационен рекуператор тип „тръба в тръба“. Дискутирани са проблемите при проектното топлотехнческо оразмеряване на тези утилизационни съоръжения, както и препоръчваните в литературата граници за избор на скоростите при нормални условия на преминаващите през тях димни газове и въздух. Основните изчисления са проведени посредством собствен софтуерен продукт. Анализът на придобитите данни показва, че част от тях има потвърдителен характер, но има и такива, които не са съвсем очаквани най-вече в количествено отношение. Последните са коментирани и въз основа на тях са формулирани някои конкретни изводи и препоръки за по-уверено коригиране на първоначално зададените стойности на показателите, определящи аеродинамичното натоварване на радиационен рекуператор.

Ключови думи: радиационни рекуператори, енергия, екология, ефективност.

Received January 07, 2019

(c) Инженерни науки, год. LVI, 2019, № 1 